\title{
CRIAÇÃO DOS SISTEMAS MUNICIPAIS DE ENSINO
}

\author{
Diva Chaves Sarmento*
}

\begin{abstract}
RESUMO: A criação dos sistemas municipais de ensino tornou-se possível a partir da nova Constituição e da nova Lei de Diretrizes e Bases da Educação Nacional. A legislação previa, também, como opção do município criar seu próprio sistema ou compor com o Estado um sistema único ou, ainda, manter-se integrado ao sistema estadual. O presente texto trata da criação do sistema de ensino em nove municípios de Minas Gerais. Por meio de análise documental, questionários e entrevistas foi possível observar que a criação dos sistemas municipais de ensino significa uma opção do município para assumir sua autonomia e abre possibilidade de maior participação social nas decisóes de política local. Um estudo sobre essa realidade precisa levar em conta o pacto federativo, as desigualdades regionais e as relações internacionais. $\mathrm{O}$ Brasil precisa consolidar o seu sistema e ao mesmo tempo sofre pressóes para descentralizar, flexibilizar e expandir a escolarização privada. Têm sido questões permanentes: a questão federativa, as disputas ante a descentralização, a autonomia e a distribuição de competências e responsabilidades entre os entes federativos.
\end{abstract}

Palavras-chave: Sistema de ensino. Política educacional. Descentralização, autonomia e democratização.

\section{ESTABLISHMENT OF CITY TEACHING SYSTEMS}

ABSTRACT: The promulgation of the new Constitution and of the new "Lei de Diretrizes e Bases da Educação Nacional" (Brazilian Education Basic Tenets Law) allowed the establishment of City Teaching Systems. The legislation also provided that local councils could either create their own system, make up one system with the Federal Government or keep integrated to their State teaching system. The present study explores the establishment of teaching systems in nine cities in the State of Minas Gerais. Together with questionnaires and

Professora da Universidade Federal de Juiz de Fora (UfJF) e membro do Conselho Estadual de Educação de Minas Gerais. E-mail: dchaves@terra.com.br

Educ. Soc., Campinas, vol. 26, n. 93, p. 1363-1390, Set./Dez. 2005 
interviews, the analyses of documents show that the establishment of city teaching systems represented an option for local councils to assume autonomy and opened up possibilities for a greater social participation in the local political decisions. A study on this reality needs to take into consideration the federative pact, the regional inequalities, and the international relations. Brazil needs to consolidate its system but, at the same time, it is under pressure to decentralize, flexibilize and expand private schooling. Permanent issues are: the federative issue, the disputes for decentralization, autonomy, and the distribution of skills and responsibilities among the States.

Key words: Teaching system. Educational policies. Decentralization, autonomy and democratization.

7 Constituição de 1988, complementada pela Lei 9.394/96, definindo as competências e atribuições dos entes federativos União, estados e municípios, estabeleceu com clareza a autonomia do município para criar o seu próprio sistema de ensino. A legislação previu, ainda, como alternativas a essa opção, o município compor com o estado um sistema único ou manter-se integrado ao sistema estadual. A ênfase na descentralização tem sido apoiada por correntes políticas de diversas tendências em vários países. Diante disso, torna-se importante refletir sobre a constituição dos sistemas nacionais de ensino, na perspectiva de se procurar compreender a criação dos sistemas municipais. Com essa referência buscou-se analisar a criação do sistema em nove municípios do estado de Minas Gerais. Orientou o estudo o pressuposto de que a criação do sistema municipal de ensino é uma questão estreitamente relacionada ao pacto federativo no Brasil, indo além da política de municipalização, acentuada nos anos de 1990, firmando o município a sua autonomia.

\section{Sistemas educacionais: formação e crise}

A organização e a difusão da escola padronizada, pública e obrigatória, articulada em redes e sob a responsabilidade do Estado, parte da Europa e se expande pelo mundo na trilha da modernização. Candeias (2001, p. 31) traduz bem essa realidade:

Na escolarização assistimos à construção da modernidade, quer tal modernidade se reflita na formação do Estado-nação contemporâneo através da im- 
posição de uma língua e de uma história comuns, quer se trate também da construção de sociedades racionalmente organizadas e hierarquizadas em que a potenciação do desenvolvimento econômico, político e militar caraterísticos dos séculos XIX e XX é levada aos seus limites máximos.

Esse processo caracteriza o surgimento e o avanço das sociedades sob a hegemonia burguesa, com ênfase na ordem e na eficiência, com diferenciações entre países, conforme sua história, contexto político e social e sua localização no sistema mundial. Petitat (1994), preocupado com o papel atribuído à escola como produtora e reprodutora da ordem social, analisa sua evolução e suas grandes mudanças no mundo ocidental, destacando que a criação dos sistemas escolares sistematizou as divisões existentes e gerou um ponto focal na política em âmbito do Estado, tornando-o o favorito dos enfrentamentos sociopolíticos em termos de cultura, classes sociais e futuro social.

O sistema escolar também carrega e alimenta esperanças de democratização social e de libertação dos povos. A idéia da escola como direito veio se consolidando ao longo do período de sua expansão e constituição como sistema, permitindo aos defensores de uma educação democrática apontar:

O sistema de educação escolar pode afirmar-se como um lugar central de afirmação da cidadania numa sociedade comunicacional (Habermas) gerida de um modo dialógico, embora tendo sempre presente que a escola é um local de luta e de compromisso, que não se muda por decreto ou discurso teórico, como lembrava Paulo Freire. (Teodoro, 2001 p. 156)

Como espaço de lutas e de conflitos, sua organização e difusão ao longo dos séculos reflete as forças econômicas, históricas e sociais em seu entorno. Freqüentar a escola, submeter-se às suas normas, exames, mecanismos de avaliação e controle passa a ser condição de inserção social, definindo os estados os mínimos obrigatórios em termos de currículo e das faixas etárias, geralmente estabelecidas em torno dos 7 aos 12/14 anos de idade. A Escola cumpria a função de socialização, preparando cada um seletivamente para ocupar um lugar na escala social num sistema produtivo de pleno emprego e hierarquia social. A crise do Estado-nação, em consequiência da globalização da economia, refletiu na estrutura e funcionamento dos sistemas nacionais de ensino. A partir dos anos de 1970, as sociedades vêm passando por mudanças profundas em torno dos tempos, dos espaços e das lógicas de intervenção do Estado, interferindo nas relações e 
nas formas de garantir a escolarização do povo. Após a Segunda Guerra Mundial, o Estado-nação teve um papel primordial nas políticas voltadas para o desenvolvimento, acentuando a Educação como base nesse processo, junto com programas de assistência e proteção social, caracterizando, em muitos países, o Estado de Bem-Estar ou Estado Providência. O espaço nacional constituía o centro das ações políticas e econômicas voltadas para a modernização assumida como ideal universal.

As políticas educativas foram profundamente afetadas pelo esgotamento do projeto desenvolvimentista e pela globalização da economia, levando à reforma do Estado e à ampliação da influência das agências internacionais nas políticas públicas, incluindo as políticas educacionais. $\mathrm{O}$ Estado é chamado a atuar como estimulador da competição: flexibilidade, descentralização, autonomia passam a ser as novas palavras de ordem. $\mathrm{O}$ controle do sistema passa a ser feito por meio de amplos sistemas nacionais de avaliação. A teoria do capital humano é enfaticamente retomada e a educação é acentuada como base da competitividade, em detrimento do seu papel na igualdade das oportunidades sociais e na formação da cidadania.

Como diz Chesnai (1996, p. 218), após os anos 70 do século XX, "a concorrência se dá cada vez mais diretamente entre companhias, que têm necessidade imperativa de todo o espaço para se desenvolverem. A palavra chave desse regime de economia internacional é a 'competitividade". Segundo o mesmo autor, a partir da recessão americana de 1980-1981 e das medidas tomadas para defender os rendimentos do capital monetário, os países do Terceiro Mundo "foram 'nomeados' [grifo do autor] para suportar o peso da crise mundial, sendo obrigados a reorientar sua política econômica com a obrigação do ajuste estrutural". Para ele, a mundialização do capital e a pretensão de domínio do capital financeiro não apagam a existência dos Estados nacionais, mas os levam à nova configuração. Cada formação social concreta responde às imposiçōes internacionais, conforme suas condições históricas e sua localização no processo de construção histórica mundial.

\section{A formação do sistema educacional no Brasil}

A idéia de dar uma orientação e uma unidade ao ensino no Brasil data do século XIX, como notifica Fernando de Azevedo (1963), enumerando figuras políticas do Império que trataram da educação no país. Labouriau (1928), na Primeira Conferência Nacional de Educação, lem- 
brava Rui Barbosa, ao tratar da vinculação entre a organização da educação nacional e o progresso do país, resumindo a idéia na seguinte frase: "povo educado é povo capaz de produzir, é povo livre, é povo progressista”. Essa idéia foi enfatizada para justificar sua defesa da criação de um ministério da Educação que centralizasse a política nacional de educação. Enumerava outras razões além da econômica: coordenar sistematicamente os esforços em matéria de educação, organizando o ensino, e manter a unidade nacional por meio de um plano nacional de educação.

Sua defesa indicava a percepção das mudanças em curso no país que, a partir do primeiro surto industrial de 1885, vinha passando por transformação de estrutura econômica, política e social. No entanto, tais mudanças não tinham força suficiente para alterar a tradição implantada com o Ato Adicional de 1834, que, no dizer de Azevedo (1963, p. 609), “jogando a educação fundamental do plano nacional para os planos locais, subtraiu à esfera do governo federal a organização das bases em que devia assentar o sistema nacional de educação". A Constituição de 1891 consagrou o princípio federativo, transferindo a instrução primária aos estados. O governo federal reservava-se a atribuição de criar instituições do ensino secundário e superior nos estados e organizar a instrução no Distrito Federal. A descentralização política e administrativa que transferiu aos estados a responsabilidade do ensino primário, assim como os cursos normais, condicionaram sua expansão às peculiaridades e desenvolvimento econômico de cada unidade federativa. Os estados mais desenvolvidos, iniciando-se por São Paulo, adotaram, nas décadas de 1920 e 1930, políticas que levaram à organização do ensino em seu âmbito. Os sistemas estaduais e o sistema federal, restrito ao ensino secundário e superior, começaram a se organizar de forma paralela.

Nos anos de 1920/30 tem início o chamado desenvolvimentismo brasileiro de base industrial, processo que dominou a história do país até os anos de 1970/80. Foi um período marcado pela concentração do poder no Estado central, crescente urbanização, concentração da riqueza e aumento das desigualdades sociais. As mudanças e a reorganização social geraram mobilizações e reivindicações dos setores médios urbanos e da classe operária, trazendo as primeiras greves, a intensificação dos conflitos oligárquicos e a movimentação dos militares, e revelando uma insatisfação geral. As idéias e práticas educacionais tradicionais foram combatidas e não só políticos, mas também educadores, passaram a defender a necessidade de um sistema de educação público, completo, com uma 
estrutura orgânica conforme as necessidades brasileiras e as novas diretrizes econômicas e sociais.

A hegemonia mundial no pós-guerra foi disputada pelos Estados Unidos e a URSS com a vitória do primeiro, ao qual o Brasil se alinhou. Os acordos de Bretton Woods estabeleceram as bases da hegemonia americana, propiciando a expansão e a transnacionalização das grandes corporações multinacionais, com investimentos em vários países, incluindo periféricos, entre os quais o Brasil. Nesse processo a educação nacional passa a sofrer influência, também, das agências internacionais a começar pelos acordos MEC/USAID, ainda nos anos de 1960. Os governos militares, após 1968, reformaram o sistema educacional (Leis 5.540/68 e Lei $5.692 / 71$ ) na perspectiva de adequar o sistema de ensino à nova fase do desenvolvimento econômico do país. O art. 52 da Lei 5.692 determinava que a União prestaria assistência financeira aos estados e ao Distrito Federal para o desenvolvimento de seus sistemas de ensino e organizaria o sistema federal que teria caráter supletivo. Previa, ainda, que a legislação estadual estabeleceria as responsabilidades do próprio estado e dos seus municípios no desenvolvimento dos diferentes graus de ensino, visando à maior eficiência na aplicação dos recursos, sendo essas providências preparatórias para a progressiva passagem de encargo e serviços de educação, especialmente de $1^{\circ}$ grau, para a responsabilidade dos administradores locais na expectativa de um trabalho mais satisfatório (art. 58).

Ao final do período desenvolvimentista o país havia alcançado a tão ambicionada industrialização, mas a ela se somaram as contradições e as desigualdades. Essas desigualdades se refletiam nos sistemas de ensino não apenas entre as classes sociais com a dualidade não superada, como também entre os estados, não conseguindo a ação supletiva da União garantir o acesso e a eqüidade em termos educacionais a todos os brasileiros. Aplicam-se ao Brasil as observações de Antunes (2001, p. 168) em relação a Portugal:

O sistema educativo (...) apresenta-se, no final dos anos 80 como um serviço público com marcadas características de subdesenvolvimento, dados os níveis de cobertura da população que é capaz de proporcionar quer dos pontos de vista quantitativos (taxa de freqüência) quer qualitativo (taxa de sucesso nas aprendizagens e na aquisição dos diplomas).

Pode-se dizer que, também no Brasil, a partir da década de 1980, a realidade educativa caracteriza-se como um processo em simultânea cri- 
se: consolidação da escola de massas e deslocamento da política educativa da esfera da democratização para o universo da modernização. As mobilizaçôes sociais e os conflitos dentro das classes dominantes reaparecem quando o crescimento cai e o Estado se submete a um plano de estabilização acordado com o FMI, com as recomendações de descentralizar, desestatizar e conseqüente novo surto de internacionalização. Em meio a conflitos e demandas, uma intensa mobilização garantiu alguns espaços de democratização na Constituição de 1988.

\section{A Constituição de 1988, a nova LDB e os sistemas de ensino}

Com o enfraquecimento e a queda dos governos militares e o envolvimento dos diversos setores sociais na luta pela redemocratização do país, uma nova Constituição e uma nova LDB revelaram-se uma necessidade. A expectativa era de mudanças no sentido de reverter o processo capitaneado pelas forças que levaram ao "golpe de 1964". Cunha e Góes (1985) traduziram essas perspectivas, destacando propostas de reformulação do sistema educacional entendidas como as bandeiras defendidas por entidades do magistério, por sindicalistas, por associações científicas e por partidos políticos. Sintetizando as de maior alcance, enumeraram a gratuidade do ensino público em todos os níveis, a dotação automática de recursos para a educação e a aprovação de uma nova Lei de Diretrizes e Bases da Educação Nacional. Destacavam, ainda, que a LDB deveria determinar a descentralização administrativa dos sistemas educacionais, entendendo-se que o caráter unitário da escola só adquire pleno sentido no âmbito local e que essa descentralização dependeria de uma reforma tributária, contemplando os municípios e os estados de forma a permitir que assumissem suas responsabilidades com a manutenção e a ampliação do ensino público e gratuito de boa qualidade.

Estava presente na segunda metade do século XX, mesmo nos governos militares, a perspectiva de valorização do nível local, a descentralização, com sugestôes quanto à distribuição de competências entre os níveis municipal, estadual e federal. No final dos anos de 1970 e início dos de 1980, com as eleições diretas para governadores, vários estados e municípios iniciaram políticas educacionais voltadas para democratização da escola. As experiências dos municípios de Boa Esperança (ES), Lages (SC) e Piracicaba (SP) são citadas inúmeras vezes (Saviani, 1997; Lesbaupin, 2000; Teixeira, 2001) como referência de 
ação municipal do período em busca de um caminho de administração democrática. Rodrigues (1985, p. 26) destacava:

O que ocorreu no Brasil é muito similar àquilo que ocorreu na Espanha: cresceram as organizações populares, as associações de bairros, de moradores, de favelados, de consumidores, os clubes de vizinhos e as associações que congregavam interesses profissionais de entidades proibidas de terem seus sindicatos, tais como: associações de funcionários públicos, as associações dos professores e outras organizações.

A Constituição de 1988 foi elaborada e aprovada sob o impulso desses movimentos. Se no processo constituinte, a mobilização da comunidade educacional garantiu a incorporação no texto constitucional dos pontos constantes da "Carta de Goiânia”, aprovada na IV Conferência Brasileira de Educação, em 1986, o mesmo não aconteceu com a nova LDB. Saviani (1997) alertou que esta seria implantada num contexto de dificuldades para os setores populares e seus representantes progressistas, sendo-lhes a correlação de forças totalmente desfavorável. As mudanças resultaram do avanço do neoliberalismo, levando ao desmonte do Estado e fazendo emergir e clarear as contradiçóes presentes "numa luta de longa duração entre três projetos para o Brasil que estiveram presentes durante toda a história do século XX”, como bem apontou Fiori (2003, p. 10): o projeto liberal apoiado no livre cambismo, o desenvolvimentismo conservador e a vertente nacional, popular e democrática do desenvolvimentismo. Em termos educacionais, a expressão desses projetos pode ser percebida na transmutação que o projeto original de LDB foi sofrendo na Câmara. Na percepção de Saviani (1997), o projeto original caminhava em direção a uma concepção socialista, garantindo uma formação básica comum que possibilitasse a reconciliação entre o indivíduo e o cidadão. As transformaçōes operadas ao longo da tramitação na Comissão de Educação da Câmara deram ao texto aprovado caráter de uma concepção social-democrata, entendendo-se a educação como um direito social que deve ser garantido pelo Estado. A seguir setores conservadores alteraram uma das principais conquistas do projeto representada pelo Capítulo V, referente ao Sistema Nacional de Educação, atenuando seu caráter social-democrata progressista. Saviani não identifica uma concepção clara no projeto original de Darcy Ribeiro, que acabou dando base às mudanças do texto final marcado pelas orientações neoliberais dominantes nos anos de 1990. 
Saviani (1997) apontava como aspecto positivo a tentativa de se configurar um sistema nacional de educação, mas via como problemática a idéia de sistema municipal de ensino, considerando essa inclusão no próprio texto constitucional, como decorrente das dificuldades de compreensão do significado de sistema. Prevaleceu no texto final a expressão "Da organização da Educação Nacional" e no art. 8, "a União, os Estados, o Distrito Federal e os Municípios organizarão, em regime de colaboração, os respectivos sistemas de ensino". Percebem-se algumas questôes permanentes em torno do processo de constituição de um sistema educacional no Brasil: a questão federativa, as disputas em torno da descentralização administrativa do sistema de educação, a questão da autonomia, a distribuição de competências e responsabilidades entre os entes federativos. Pode-se observar um pouco dessas dificuldades analisando-se as solicitaçóes de esclarecimentos enviadas ao Conselho Nacional de Educação após a aprovação da nova LDB e os pedidos de manifestação daquele órgão em questôes relativas ao entendimento e alcance das determinações legais. Os pareceres CNE/CEB 30/2000 e 04/2001 são exemplares no sentido de evidenciar as dúvidas e dificuldades na compreensão das possibilidades abertas em relação aos sistemas municipais de ensino, sua organização e funcionamento. O Parecer 30/2000, motivado por solicitação da União Nacional de Conselhos Municipais de Educação e elaborado pelo conselheiro Jamil Cury, trata da questão dos sistemas de ensino e da organização da educação nacional firmando, a partir de ampla revisão legal e reflexão apoiada em autores que escreveram sobre o tema, o entendimento de que "Os municípios, pela Constituição de 1988, são sistemas de ensino". Embasando-se em fundamentada análise da Constituição e da Lei n. 9.394/96, o relator do Parecer 30/2000 chega à definição de sistema de ensino, um tema controverso, pelo próprio uso da palavra sistema no campo da educação com diversas acepções, como aponta Saviani (1999, p. 120). O apanhado legal leva à compreensão de sistema de ensino como:

instituições escolares responsáveis pela oferta da educação escolar dentro de níveis e etapas discriminadas, com normas educacionais que, isentas de antinomias, dêem organicidade e unidade ao conjunto sob o influxo dos princípios, finalidades, valores e deveres da educação postos na Constituição e na LDB e sob o competente órgão executivo. (Parecer CNE/CEB 30/2000).

No Parecer 04/2001, o mesmo conselheiro, a propósito de consulta encaminhada pelo Conselho Municipal de Educação de São Paulo, 
em outubro de 2000, reafirma o entendimento de respeito à autonomia dos entes federativos quanto à organização de seus órgãos normativos e executivos, resguardando-se os marcos legais, no desempenho da incumbência de ativar os "recursos capazes de pôr em ação todos os sujeitos implicados no direito dos cidadãos brasileiros ao saber, aos conhecimentos, aos valores, às habilidades e competências que a escola pode propiciar" (Parecer CNE/CEB 04/200l).

Apesar do esforço do Conselho Nacional de Educação em dirimir dúvidas e firmar posiçôes, dadas as mudanças decorrentes da globalização, da crise do Estado-nação e da situação do Brasil como país emergente no contexto internacional com as crescentes demandas em torno da educação, acredita-se que as questões referentes à organização dos sistemas de ensino, suas competências e responsabilidades não são assunto encerrado.

\section{A criação dos sistemas municipais de ensino}

O movimento pela autonomia municipal em educação teve expressão clara nos anos de 1980 com a criação, em 1986, da União Nacional dos Dirigentes Municipais de Educação (UNDiME). Logo após a aprovação da nova LDB, a entidade realizou o seu $6^{\circ}$ Fórum Nacional, sendo destacadas a questão da autonomia municipal e a possibilidade aberta para os municípios organizarem sistemas próprios. Pode-se perceber um aumento da ação dos municípios para garantir recursos e espaços de participação na defesa dos interesses locais, sendo possível entender o reconhecimento do município como ente jurídico autônomo na Constituição de 1988 como uma conquista. Foram definidas competências, responsabilidades, recursos financeiros e direitos, colocando o município como ente federativo a atuar em regime de colaboração com o estado e a União.

Com a nova Constituição, comemorava-se a redemocratização do país e os avanços na conquista da cidadania. Lesbaupin (2000), analisando a experiência de prefeituras democráticas, mostrava, a partir de meados dos anos de 1980, a crescente valorização da participação dos movimentos sociais na definição das políticas públicas locais, a condenação ao autoritarismo com propostas de uma democracia substantiva que ultrapassava os marcos da representação parlamentar. Mostrava ainda mudanças no comportamento da esquerda, passando a combinar reivindicação com interlocução direta com as agências estatais; discussão e negociação de prioridades por meio de plenárias populares organizadas, orçamento 
participativo, participação semidireta na gestão por intermédio de conselhos setoriais. Identificava haver em curso um processo de descentralização e de valorização dos governos locais, entendendo-se as experiências analisadas como inovações que vêm se contrapondo ao padrão neoliberal, apontando para mudanças qualitativas nas relações e práticas do governo local. $\mathrm{O}$ autor reconhecia que o incentivo à descentralização faz parte do intento neoliberal de desonerar o governo federal, que centraliza os recursos e repassa responsabilidades tanto a governos estaduais, como a governos municipais e, também, a organizaçôes não-governamentais (oNGs). Mas a descentralização tanto pode significar maior participação, mais cidadania, ampliação do processo democrático, como pode restringir a democracia.

Analisando o desenvolvimento da luta pela implantação de um sistema nacional de educação no Brasil, verifica-se que a descentralização tem sido apoiada tanto por conservadores como por progressistas. $\mathrm{O}$ município tem sido apontado como um campo potencializador de experiências democráticas, pela proximidade do governo local com os cidadãos. Por outro lado, a adoção de políticas neoliberais nos anos de 1990 estimulou o repasse de responsabilidades para os municípios sem considerar suas reais condições de administração. A criação de sistema municipal surgiu como possibilidade ao mesmo tempo em que os estados ampliavam a política de municipalização incentivada pela NEC n. 14/96 e Lei 9424/ 96, criando o Fundo de Desenvolvimento do Ensino Fundamental e de Valorização do Magistério (FUNDEF). O conceito de municipalização passou a permear as políticas de educação, confundindo-se algumas vezes com o de sistema municipal.

$\mathrm{Na}$ área educacional a descentralização e a autonomia eram defendidas pelos educadores nos anos 1980 como contraposição ao autoritarismo. Mas, mesmo aqueles identificados como progressistas, entendiam ser uma importante conquista a constituição de um sistema nacional de educação "público, gratuito e de qualidade" para todos, defendido como direito do cidadão e dever do Estado, abrindo possibilidades de democratização e mobilidade social. A definição de competências e responsabilidades entre as esferas de governo não excluía a responsabilidade do governo central de estabelecer as "diretrizes e bases" em âmbito nacional nem de garantir seu cumprimento e extensão a toda a federação, inclusive com os recursos necessários. No entanto, havia divergências quanto ao fato de a descentralização chegar ao nível municipal, tanto entre educadores como entre políticos. Nesse sentido, a criação dos sistemas municipais de ensino pode 
ser entendida como a opção do município em assumir a autonomia em relação à política educacional, uma vez que pressupóe uma decisão pautada em lei, devendo ser interesse do executivo, aprovada pelo legislativo e contar com a participação de setores das comunidades nos Conselhos $\mathrm{Mu}$ nicipais de Educação, parte integrante do sistema. Na prática, os processos de municipalização e de criação dos sistemas têm se confundido. Uma pequena análise da realidade em três dos maiores estados da federação pode auxiliar a compreensão do anunciado.

\section{Rio Grande do Sul, São Paulo, Minas Gerais}

Mello (1988) argumentava que o disposto no parágrafo único do art. 58 da Lei 5.692/71 "pegou" em algumas regiões e não "pegou” em outras, sendo mais freqüente nas regiōes mais pobres, onde a população e o magistério têm menor poder de pressão, principalmente em estados do Nordeste e nas escola rurais. Acrescentava: "a municipalização não ocorreu, ou ocorreu em aspectos muito específicos, nos estados cujos sistemas eram mais consolidados" (1988, p. 52).

Analisando-se três publicações posteriores à aprovação da nova LDB, uma do Rio Grande do Sul, outra de São Paulo e outra de Minas Gerais, pode-se perceber as diferentes formas de política em relação à questão em pauta.

A publicação da Federação dos Municípios do Rio Grande do Sul foi elaborada por Sari \& Kirst (1997), tendo o objetivo de contribuir para que os municípios avançassem na construção da educação de qualidade a ser garantida a todos os cidadãos. Tratava das responsabilidades do município com a educação, da organização da educação no âmbito do município, dos recursos financeiros para a educação, de sua aplicação em manutenção e desenvolvimento do ensino, da municipalização e do desafio da qualidade e da organização e funcionamento do Conselho $\mathrm{Mu}-$ nicipal de Educação. Chama a atenção, inicialmente, não haver um item sobre os sistemas municipais de ensino. Ao ler o texto, verifica-se que a Constituição do Rio Grande do Sul, no art. 34 do Ato das Disposições Constitucionais Transitórias, estabelecia:

O Estado, ao requerer que o Município comprove a aplicação mínima de $25 \%$ de sua receita de impostos, a existência e funcionamento de Plano de Carreira do Magistério e de Conselho Municipal de Educação, além 
de Plano Municipal de Educação, pressupõe uma organização do ensino estruturada e com grau elevado de autonomia. A esta organização denomina-se Sistema Municipal de Ensino. (Sari \& Kirst, 1997, p. 12. Grifo da autora)

Esse dispositivo foi entendido pelas autoras como determinante da organização do Sistema Municipal de Ensino. Todo o teor da publicação está calcado no entendimento de que a consolidação dos sistemas municipais seria o desafio das novas administrações. Ao tratarem do Conselho Municipal de Educação, registravam o fato de a bibliografia sobre o tema destacar o pioneirismo do estado na sua organização e nas discussões sobre sistemas municipais de ensino. Reconheciam que o número de conselhos vinha crescendo e a existência de avanços na área. Consideravam que a Constituição Federal de 1988 significou um reforço, facultando a organização do Sistema Municipal de Ensino, tendo a Constituição Estadual reafirmado o preceito federal, exigindo dos municípios, entre outros requisitos básicos, a comprovação da existência legal e do funcionamento do Conselho Municipal de Educação.

O livro, organizado por Giubilei (2001), resultou de uma pesquisa integrada, envolvendo dez municípios do estado de São Paulo, com o objetivo de investigar, analisar, acompanhar e avaliar o processo de municipalização do ensino como componente essencial das políticas de descentralização. Verifica-se que foram municipalizados programas como a merenda escolar, o transporte de alunos, as construções escolares, a contratação de funcionários, escolas e ensino fundamental da primeira à quarta série. Apesar das pesquisas se apresentarem como parte de uma investigação articulada, cada uma focalizou um aspecto em municípios diferentes. A que oferece mais subsídios para o entendimento do processo no estado teve como problema central identificar o significado da municipalização do ensino para os responsáveis pela gestão da educação (Silva, 2001). Foram pesquisados quatro municípios e a conclusão aponta para alguns aspectos significativos: os municípios estavam perdendo recursos com a implantação do FUNDEF; a municipalização foi entendida como expressão de uma vontade impositiva do estado transferindo aos municípios a responsabilidade pelo ensino fundamental; a municipalização, embora induzida, possibilita ganhos políticos ao ensejar maior participação da comunidade, descentralização e proximidade com o processo decisório, bem como a ampliação dos espaços de vivência democrática; foi identificado o receio de a municipalização do ensino significar um certo 
regionalismo, tornando a realidade nacional multifacetada; a preocupação dos gestores é grande com a questão financeira, temendo problemas com o repasse de recursos inviabilizando as ações para a implementação da política educacional. A criação de sistema municipal de ensino ficou em segundo plano.

Historicamente, o processo de municipalização no estado de São Paulo tem mostrado a tendência a se manter o ensino fundamental e médio na rede estadual, transferindo aos municípios a educação infantil e a de jovens e adultos. A criação do FUNDEF, com a delimitação dos recursos e de sua aplicação, colocou o município ante a opção de perder recursos ou assumir o ensino fundamental. Essa realidade foi percebida como imposição e encontrou os municípios despreparados para assumirem as novas responsabilidades. A municipalização induzida ofuscou a compreensão do significado de se criar um Sistema Municipal de Ensino como opção autônoma na condução da política educacional. A pesquisa mostrou que um sistema único no âmbito municipal, com escolas responsáveis por todo o ensino fundamental, democraticamente administrado, é o ideal a ser alcançado. Pode-se inferir que a organização dos municípios e sua integração em entidades e associações desempenham um papel mais importante no trato da municipalização e criação de sistema próprio do que o fato de o estado ser rico ou pobre.

O Parecer n. 500/98 foi elaborado pelo Conselho Estadual de Educação de Minas Gerais e apresentou-se como orientador da organização dos Sistemas Municipais de Ensino. Mostrava-se o Conselho extremamente cuidadoso em nada impor, nem mesmo interferir nas decisões municipais, mas possibilitar que os municípios refletissem sobre o significado da decisão de criar ou não sistemas municipais de ensino e sobre as alternativas para regulamentá-los. Destaca-se, como um dos principais fundamentos da Constituição Federal, a união indissolúvel dos entes federativos, pressupondo que todos gozarão de autonomia para o exercício de suas responsabilidades. Houve a preocupação de se discutir o significado de "sistema" de modo a demonstrar a necessária articulação entre os entes federativos para garantir a unidade nacional. Nessa perspectiva, partia-se da conclusão de que no Brasil não se teve, ainda, um sistema nacional organizado. O Parecer chamava a atenção ainda para as duas exigências do mundo contemporâneo a serem consideradas: o fenômeno da globalização e a demanda crescente das comunidades quanto à preservação da cultura local assegurando seus valores, sua autonomia e sua parti- 
cipação na formulação das políticas públicas. O CEE/MG buscava resguardar a unidade na diversidade, procurando contribuir para a construção de sistemas municipais de ensino autônomos e flexíveis, mas articulados e integrados, resguardando os padrões comuns necessários para que os cidadãos possam ter mobilidade geográfica, participação na vida nacional e acontecimentos internacionais, sem perder sua identidade e sua capacidade de escolha das políticas que mais convenham à cultura e às condições da realidade local. Intencionalidade, articulação, gestão democrática, descentralização, autonomia, universalização e controle social são os aspectos enfatizados.

É importante lembrar que no período de 1991 a 1998 a Secretaria de Estado de Educação de Minas Gerais desenvolveu uma política de municipalização do ensino fundamental e da educação infantil, que só não foi mais intensa pela atuação da UNDIME/MG, orientando e articulando os municípios nas negociaçóes com o estado. Mesmo assim, a municipalização criou dificuldades para muitos municípios que tentaram reverter o processo na gestão 1999-2002 e também criou problemas para o estado.

Essa rápida análise do processo de desenvolvimento das políticas educacionais em três estados da Federação mostra que não só os países respondem às pressões externas pela descentralização e reorganização administrativa do mundo globalizado, conforme sua história e condições. $\mathrm{O}$ mesmo acontece com os estados numa unidade federada. A organização dos sistemas municipais de ensino, como integrantes dos sistemas estadual e federal, envolve questóes relacionadas ao poder local e significado ante o processo de globalização.

\section{Poder local: possibilidades e limites}

No prefácio à edição brasileira de Para além do capital, Mészaros (2002, p. 31-32) expressa sua convicção de que:

O futuro do socialismo será decidido nos EUA (...). Na mesma entrevista, disse ele, enfatizei o fato de que o fermento social e intelectual na América Latina promete para o futuro mais do que podemos encontrar atualmente nos países capitalistas avançados. Isto é compreensível, já que a necessidade de mudança radical é muito mais urgente na América Latina do que na Europa e nos EUA, e as soluçôes prometidas da 'modernização' e 'desenvolvimento' demonstram não passar de uma luz que se 
afasta num túnel cada vez mais longo (...). O Brasil como país econômica e politicamente mais importante, ocupa uma posição proeminente nesse quadro.

Giddens (1999, p. 56-57) argumenta: "o neoliberalismo empreendeu uma crítica constante do papel do governo na vida social e econômica, crítica que parece encontrar ressonâncias em tendências do mundo real”. Desafia os social-democratas a lançarem um contra-ataque a tais idéias, que não se sustentam quando examinadas de perto. A seguir, o autor enumera o que o governo pode realizar no mundo contemporâneo no sentido de demonstrar que Estado e governo não se tornaram irrelevantes. Entre as inúmeras tarefas apontadas encontra-se: "promover o desenvolvimento ativo do capital humano através de seu papel essencial no sistema de educação". Destaca, também, a importância do sistema educacional no propósito civilizatório que o Estado pode exercer ajudando a moldar normas e valores.

O mesmo autor, ao discutir os conceitos de esquerda e de direita no mundo contemporâneo, recorre a Bobbio para afirmar a permanência da distinção, tendo a desigualdade no seu cerne. Enquanto a direita aceita a desigualdade e a hierarquia, a esquerda defende a idéia de igualdade e a justiça social. Contudo, Giddens propõe um refinamento na definição de Bobbio, acrescentando que é "mais preciso dizer que ser de esquerda é acreditar numa política de emancipação” (1997, p. 57).

Castells (1999) chama a atenção para o avanço do capitalismo informacional, mostrando que a integração dos países em uma economia global liga os destinos do Estado em cada nação à concorrência econômica das empresas nacionais ou localizadas em território nacional, havendo uma nova forma de intervenção estatal na economia, que une a competitividade, a produtividade e a tecnologia de forma explícita. $\mathrm{O}$ analfabetismo e a falta de instrução de uma grande parte dos brasileiros são apontados pelo autor como fatores de enfraquecimento do processo de reestruturação econômica e reforma social em busca do novo desenvolvimento.

Toda essa realidade, complexa, incerta, desafiadora, influencia as políticas educacionais, a organização e funcionamento do sistema de ensino, visto, sob qualquer ângulo, como espaço fundamental de atuação. A pressão pela competitividade tem levado a União e alguns estados a reformarem seu sistema de ensino. No âmbito dos municípios apareceram experiências visando ao resgate da cidadania: Porto Alegre com a Es- 
cola Cidadã, Belo Horizonte com a Escola Plural, para citar as mais conhecidas. Muitas cidades, palco das conseqüências sociais das mudanças em curso (desemprego, pobreza, aumento da insegurança e violência), passaram a buscar alternativas de políticas sociais que dessem conta das carências e das contradições.

No Brasil pode-se identificar a emergência de algumas propostas inovadoras, introduzindo a experiência de descentralização administrativa desde os anos de 1970. Divisão do município em regiões, criação de conselhos setoriais, orçamento participativo, planejamento estratégico, fóruns de entidades de moradores, audiências públicas e conferências públicas têm sido adotados por prefeituras de diferentes vinculaçôes políticas. São iniciativas que visam ampliar a participação direta dos vários segmentos sociais na definição, gestão e controle das ações públicas no âmbito municipal, e a melhor aplicação dos recursos públicos. Algumas iniciativas têm um cunho mais democratizante, como o orçamento participativo. Outras, como o planejamento estratégico, objetivam tornar as cidades mais competitivas, estimulando parcerias entre os setores públicos e os privados para a retomada do desenvolvimento econômico. Mesmo nesse caso, percebe-se que uma cidade competitiva deve ser capaz de integrar em termos socioculturais a grande maioria de sua população. Há uma reivindicação histórica de autonomia que se amplia para que o governo local possa ser capaz de dar respostas aos desafios urbanos. Como ressalta Borja (1997, p. 87), "a autonomia local tem sido entendida como a proteção legal da capacidade de se auto-organizar, das competências exclusivas e específicas, do direito de atuar em todos os campos de interesse geral da cidadania e da disponibilidade de recursos próprios". Constata-se uma revalorização do poder local em contraposição às conseqüências da globalização, dificultando a satisfação das demandas pelos governos centrais. Os estudiosos do poder local reconhecem, em muitas dessas iniciativas, o potencial de democratização do poder público e que "alguns governos municipais têm conseguido reverter em seus municípios o processo de exclusão promovendo a inclusão de setores sociais desfavorecidos" (Lesbaupin, 2000, p. 7). O mesmo autor argumenta que é possível e desejável a presença de democracia direta, articulada com a democracia representativa e que a prática da democracia está tornando as pessoas mais conscientes de seus direitos, mais capazes de exigi-los. Teixeira chama a atenção para a necessidade de delimitar o conceito de participação e para isso diz: 
é fundamental considerar o poder político, que não se confunde com autoridade ou Estado, mas supõe uma relação em que atores, com recursos disponíveis nos espaços públicos, fazem valer seus interesses, aspiraçōes e valores, construindo suas identidades, afirmando-se como sujeitos de direitos e obrigações. (Teixeira, 2001, p. 26)

Não se desconhece, por outro lado, que a ênfase no poder local tem contribuído para justificar políticas neoliberais de desoneração do Estado central e para manter as práticas clientelistas, ainda muito presentes na cultura brasileira. Todavia, procura-se analisar como as experiências de participação e autonomia podem contribuir para ampliar a democratização e as soluções dos problemas sociais. $\mathrm{Na}$ área da educação e da saúde há um reconhecimento da necessidade de políticas integradas ao governo central. Reconhece-se, também, que cada vez mais as políticas são globalizadas e o âmbito da esfera local é reduzido, sendo necessário ampliar articulações para evitar o localismo. Nesse sentido, Bauman (1999, p. 8), um crítico da globalização, afirma: "ser local num mundo globalizado é sinal de privação e de degradação social". Acrescenta: "as localidades estão perdendo a capacidade de gerar e negociar sentidos e se tornam cada vez mais dependentes de ações que dão e interpretam sentidos, ações que elas não controlam". Mostra que "localidade" no mundo da alta velocidade, no mundo da globalização informacional não é o que localidade significava quando a informação se movia apenas com os corpos de seus portadores, ressaltando que a globalização tanto divide quanto une.

Sendo a escola e o sistema de ensino atravessados por múltiplas determinações, ambos se vêem hoje na confluência do global e do local. No período desenvolvimentista, o Estado desempenhava o papel de Estado educador em nome de uma democratização social baseada no princípio da igualdade de oportunidades. A busca pela descentralização e pela autonomia na perspectiva de ampliar os espaços democráticos é revertida pelos interesses neoliberais de descompromissar o Estado.

No entanto, esse não é um processo simples. Os direitos políticos e sociais passaram a ser reconhecidos no confronto de movimentos dos trabalhadores. Como diz Mészaros (2002, p. 23): "um movimento que operava no âmbito das premissas estruturais do sistema do capital, como um interlocutor legalmente constituído e regulado pelo Estado". Hoje, o capital vem retomando as concessóes sob a pressão da crise estrutural por meio de leis autoritárias contrárias ao movimento sindical, cujas conquistas foram aprovadas democraticamente. São da natureza do capital a hie- 
rarquia e a centralização. Mesmo reconhecendo as imensas dificuldades do tempo presente com a globalização e suas forças incontroláveis, o autor percebe manifestações encorajadoras nos movimentos sociais em várias partes, destacando os da América Latina. Anota que já surgiu na agenda histórica a questão da igualdade substantiva em oposição à igualdade formal e à pronunciada desigualdade hierárquica dos processos de tomada de decisão do capital.

Bobbio (1986, p. 56-60) destaca: "hoje, se se quer apontar um índice do desenvolvimento democrático este não pode mais ser o número de pessoas que têm direito de votar, mas o número de instâncias (diversas daquelas políticas) nas quais se exerce o direito de voto". Depois de tratar da questão do pluralismo decorrente dos vários centros de poder presentes na sociedade contemporânea, argumenta que a democracia significa a luta contra o abuso de poder que "parte do alto em nome do poder que vem de baixo e contra o poder concentrado em nome do poder distribuído". Verifica-se assim que descentralização e autonomia só podem ser entendidas analisando-se os valores e as condições objetivas que as sustentam.

No Brasil, a tradição política centralista sempre foi confrontada pelas forças dos estados no processo federativo. Nas últimas décadas, os municipalistas vêm ganhando espaço. Não se pode perder de vista o clientelismo, o paternalismo e os interesses paroquiais na história política e social do país nas relações entre os entes federativos e entre estes e o povo. Por outro lado, têm crescido os movimentos sociais, embora a maioria da população ainda tenha uma visão segmentada da realidade e pouca organização.

Stoer (2001), professor da Universidade do Porto e participante da pesquisa "A transnacionalização dos mecanismos de regulação social e o seu impacto sobre a reforma do sistema educativo e sobre os processos educativos" em Portugal, considera que a educação para a cidadania terá que ser baseada, necessariamente, quer no pilar dos direitos e deveres do contrato social que permitiu a concretização das promessas da modernidade (...), quer num outro pilar, o de um contrato social novo, ainda em negociação, que veiculará o processo de globalização.

O estudo sobre Sistema Municipal de Ensino, nos nove municípios de Minas Gerais que o criaram entre 1997 e 2000, pretendeu conhecer as características desses municípios, o processo percorrido para a criação desses sistemas, os princípios que sustentam a sua criação e 
funcionamento, na expectativa de identificar como a autonomia e os espaços de cidadania estão sendo construídos. Além disso, esperava-se identificar os mecanismos de interação entre as instâncias municipal, estadual e federal, assim como as possibilidades e limites de cooperação estabelecidas em lei. Compreender um pouco dessa realidade pode ajudar no entendimento do seu potencial na direção da descentralização, autonomia e democratização do sistema escolar. O estudo iniciou-se pelo levantamento das informações para caracterizar os municípios e os processos adotados com a implantação dos sistemas. A seguir foi realizada análise documental das leis de criação do Sistema e do Conselho Municipal de Educação em cada município, das atas das reuniões do legislativo durante a tramitação do processo, das normas aprovadas e dos regimentos dos conselhos municipais de educação. Com base nas informações iniciais foi elaborado um questionário solicitando às secretarias municipais de educação informaçôes complementares tendo em vista os objetivos da pesquisa. Do estudo desses dados caminhou-se para o aprofundamento de algumas questões por meio de entrevistas com os dirigentes na época da criação do sistema.

\section{O município e o Sistema}

Os municípios pesquisados apresentam-se de forma bastante diferenciada em suas características. Em relação ao tamanho da população encontram-se municípios com pouco mais de 16 mil habitantes, passando por cidade em torno de 250 mil, até uma com mais de dois milhōes de habitantes. O comércio é apontado como atividade econômica básica, mas duas centram-se no comércio e nos serviços. Uma outra tem a indústria como seu forte, outra envolve agricultura, agroindústria, comércio, serviços e exportação e as demais, agroindústria e agricultura. A abrangência dos sistemas municipais em relação à demanda por educação pública é também diferenciada. $\mathrm{O}$ de maior abrangência responde por $66 \%$ da matrícula e o de menor por $20 \%$. O acréscimo das escolas infantis particulares também difere de um município para outro, variando entre $4 \%$ a $46 \%$ do tamanho da rede. Em relação à vinculação partidária dos prefeitos, à época da instituição do sistema, observou-se que eles pertenciam a partidos de diferentes orientaçôes políticas. Os aspectos que mais aproximaram os municípios foram os índices de urbanização e de alfabetização, bem próximos ou acima de 90\%. Apenas um apre- 
sentava $44 \%$ da população na zona rural e taxa de alfabetização em torno de $75 \%$.

Em todos os municípios a instituição do sistema foi iniciativa do Executivo e contou com a adesão da Câmara de Vereadores, tendo a lei de criação sido aprovada por ampla maioria ou por unanimidade sem grandes discussões. Em relação aos princípios orientadores do sistema e sua composição, a LDB foi respeitada integralmente, sem nenhuma inovação. Os conselhos municipais de educação foram valorizados, sendo sua composição e competências detalhadas na própria lei de criação ou em lei complementar. Todos são vistos como parte fundamental do sistema e destacados como espaço de participação da sociedade. Possuem caráter consultivo e deliberativo e, com exceção de um, lhes foi atribuída a função normativa. Algumas representações aparecem em quase todos: o dirigente ou representante do órgão municipal de educação, professores, os pais de alunos e diretores de escolas. Nos conselhos criados após a LDB, aparece representação de setores sociais não diretamente vinculados à área educacional, como a OAB, clubes de serviços, associações comerciais, entre outros.

Em termos de competências, as mais freqüentes são: manifestar-se sobre o plano plurianual e o orçamento, fiscalizando a aplicação de recursos, diagnosticar os problemas do ensino e propor alternativas para superá-los. São presentes, ainda, as competências para normalizar sobre autorização e funcionamento de escolas; estabelecer critérios para a proposta pedagógica e sugerir medidas para a melhoria da qualidade do ensino. Ainda bem presentes estão as competências de participar da elaboração da política educacional, acompanhar o cadastro e o recenseamento de matrículas, pronunciar-se sobre ampliação da rede e localização de prédios escolares. Opinar sobre as formas de cooperação União, estado e município ou articular com os conselhos nacional e estadual de educação foram preocupações de três dos municípios pesquisados. Observa-se um núcleo comum de competências ligadas às questões de política educacional, recursos, qualidade do ensino, autorização e funcionamento de escolas que estão presentes na maioria dos conselhos. Outras atendem à especificidade local.

A criação do Sistema Municipal de Educação possibilitou aos municípios usarem sua autonomia para encaminhamento das questôes referentes a sua área de atuação: educação infantil e ensino fundamental (art. 11 da LDB). Em geral, os municípios consideraram que se tornou possível estruturar melhor a rede escolar municipal, contribuindo para a solu- 
ção dos principais problemas na área da educação. Os valores e a cultura locais foram fortalecidos, permitindo a adequação do ensino à realidade da região. Em relação à cooperação entre os entes federativos, a maioria considerou que ela tornou-se possível exigindo maior entrosamento entre as autoridades responsáveis. As principais dificuldades encontradas decorreram da falta de informações sobre sua estrutura, organização e funcionamento. Em alguns casos, dificuldades financeiras comprometeram a ampliação de equipes e serviços na administração do sistema e acompanhamento das escolas.

\section{Participação, autonomia, democratização}

A participação foi o aspecto mais realçado tanto na decisão de se criar o sistema como na organização do Conselho Municipal de Educação: ora foi destacada como motivadora da decisão, ora como possibilidade de ser ampliada a partir da nova organização. A instituição dos sistemas não foi um ato isolado, pois em todos os municípios foram identificadas práticas de alargamento dos espaços de participação social e política: conselhos setoriais, congressos, conferências, orçamento participativo, planejamento estratégico, fóruns de entidades de moradores, etc.

As políticas indutoras da municipalização estão levando os governos locais a assumirem a sua independência e soberania afirmando o pacto federativo recuperado pela Constituição de 1988, ao reconhecer o município como ente federativo autônomo, definir suas atribuições e competências e suas bases fiscais. No entanto, é importante refletir sobre o significado dos sistemas municipais diante do nacional. Com o atual quadro da globalização e do federalismo vigente no país, como ficam realmente as possibilidades democráticas? Quais os riscos da fragmentação?

$\mathrm{O}$ processo de descentralização vem ocorrendo na maioria dos países, mas como ressalta Teixeira (2001), nem sempre acompanhado de mecanismos efetivos de participação, constituindo-se em muitos casos como forma de legitimar governos. As políticas de ajustes e as instituições internacionais (FMI, Banco Mundial) têm sido grandes incentivadoras desse processo na linha da reforma do Estado.

As mudanças municipais ocorreram em resposta às mudanças de política no âmbito federal. No entanto, o rumo dado à apropriação das novas possibilidades depende da conjuntura municipal em termos de 
desenvolvimento econômico, social e orientação política do partido no poder. Tradicionalmente, a descentralização veio ocorrendo a partir de decisões do governo federal na formulação e implementação de programas de transferência de responsabilidades para os governos locais. Os municípios que optaram pela criação do sistema assumiram sua autonomia e a participação foi valorizada, mas foi possível perceber diferenças entre eles. Nos municípios que vieram respondendo afirmativamente às políticas de municipalização ao longo das últimas décadas e que contavam com uma rede estruturada de escolas, inclusive três com conselho de educação em funcionamento desde a década de 1980, a política atual de municipalização foi enfrentada com a criação do sistema, significando a confirmação de uma autonomia que já vinha sendo gestada ao longo do tempo.

A vinculação partidária do Executivo foi outro aspecto observado na forma de condução do processo, sendo que nos municípios sob administração de partidos populares (PTB, PSB) as discussões e participação da sociedade envolveram círculos mais amplos. Em municípios sob administração de partidos mais conservadores como PFL, por exemplo, a decisão de implantar o sistema veio de cima para baixo, decisão de gabinete, e a tentativa de envolver a população nem sempre se traduziu em resultados efetivos. Em município administrado alternativamente por partidos progressistas há alguns anos, Como O PT e o PSB, a participação foi ampliada e vem crescendo. Mesmo onde a decisão contou com pouca participação popular, a autonomia tem sido valorizada e tem levado à busca de alternativas para enfrentar as responsabilidades que lhes foram atribuídas e a participação da sociedade é destacada. Há preocupações com o problema da continuidade, tendo em vista as mudanças de governo.

Outro aspecto a ser considerado é a valorização do planejamento por parte dos municípios. A maioria informou ter realizado planejamento estratégico. Dois deles inspiraram-se na experiência de Barcelona e outras da mesma natureza. Não foi possível nos demais identificar se o processo foi cumprido em toda a sua complexidade, mas percebe-se a intenção de racionalizar a aplicação de recursos para o atendimento às demandas da população e a preocupação em dar transparência às ações governamentais. O planejamento estratégico e o orçamento participativo, embora de natureza diferente, têm se confundido numa mesma administração. As motivações que estão na base dos processos de descentra- 
lização e de autonomia são marcadas pelas pressões externas e pelas características da história brasileira. Em alguns casos, podem servir à legitimação de governos e a interesses de desconcentração de tarefas e, em outros, têm significado aumento de participação nas decisões e controle das políticas públicas. A preocupação com o localismo, levando ao isolamento do contexto nacional e internacional, também tem sido evidenciada. A UNDIME tem sido a referência no sentido da articulação regional e nacional. Municípios maiores estão vinculados a redes internacionais como a das Mercocidades e a Associação Internacional das Cidades Educadoras, entre outras.

\section{Considerações finais}

O Brasil enfrenta no início do século XXI o problema de estruturar o seu Sistema Nacional de Educação, proporcionando educação básica para todos, com três sistemas autônomos que devem atuar em cooperação: União, estados e municípios. Essa tarefa é dificultada pelos problemas da Federação com suas diversidades regionais e políticas, extremas desigualdades sociais e diferentes propostas. Essas diferenças condicionam a superação das desigualdades regionais e a constituição dos sistemas estaduais e municipais do ensino. Ao mesmo tempo vê-se atravessado pelas pressões da globalização e do neoliberalismo, com a reforma do Estado levando às mudanças na política educacional para dar suporte às exigências da competição em âmbito internacional. Os sistemas nacionais de avaliação ganham realce e tornam explícitas as condições e as dificuldades de se garantir educação de qualidade para todos, questões apontadas há tempos por estudiosos da área e decorrentes da natureza do sistema capitalista e da sociedade burguesa, em que a igualdade de oportunidades significa igualdade formal, meritocrática, legitimando o caráter seletivo e excludente da Educação.

Nas últimas décadas, vários municípios têm realizado propostas inovadoras e buscado alternativas para diminuir as diferenças sociais em seu âmbito e a educação tem se mantido como uma questão prioritária nos discursos políticos. Os projetos que procuram avançar no sentido de ampliar as oportunidades de educação de qualidade para todos, com maior participação social nas decisões de política educacional, têm sido desenvolvidos por municípios administrados por partidos progressistas, embora a descentralização seja incentivada por políticos de todas as tendências. $\mathrm{O}$ 
ideal a ser alcançado no âmbito municipal foi identificado por Silva (2001) nos municípios paulistas: a escola única municipal sob um sistema responsável por todo o ensino, com a superação de diferentes redes, da fragmentação em ciclos e democraticamente administrado. Há um risco evidente de ampliação da dualidade e das desigualdades se os municípios ficarem restritos às séries iniciais do ensino fundamental e à educação da periferia ou sem condições e recursos para manter a qualidade de suas propostas de ensino, principalmente nos estados mais pobres da Federação.

Numa análise do processo de municipalização a partir dos anos de 1970, nota-se um movimento semelhante, embora diferenciado no tempo: incorporação de serviços (merenda, transporte, reforma e construção de prédios escolares), de escolas da zona rural e periferias urbanas, da educação infantil e das séries iniciais do ensino fundamental. Essa trajetória mostra as ações municipais como respostas às políticas de indução dos governos centrais. A criação da UNDIME e, posteriormente, a constituição dos sistemas municipais de ensino têm representado um movimento de resistência às políticas orientadas de cima para baixo e uma afirmação de autonomia. Os municípios com maior avanço estão procurando organizar o sistema e definindo proposta de educação para sua rede, buscando superar a divisão do ensino fundamental entre estado e município, com visão mais ampla da questão educacional. A participação da comunidade local nos conselhos, conferências públicas, fóruns de entidades de moradores e outros espaços públicos tem sido condição para a conquista da autonomia e da democratização.

Há muitas perguntas e poucas respostas. É uma linha de estudos que precisa ter continuidade, focalizando outros estados da Federação, o desenvolvimento dos sistemas municipais de ensino, a articulação com o Estado e a União, a ação supletiva da União, a atuação dos conselhos municipais, a participação da comunidade, as articulações em redes, enfim os limites e as possibilidades que se abrem.

Recebido em setembro de 2004 e aprovado em abril de 2005.

\section{Referências bibliográficas}

ANTUNES, F. Os locais das escolas profissionais: novos papéis para o Estado e a europeização das políticas educativas. In: Stoer, S.; CorTe- 
SÃo, L.; Correia, J. (Org.). Transnacionalização da educação: da crise da educação à "educação" da crise. Porto: Afrontamento, 2001. p. 163-208. AZEVEDO, F. A cultura brasileira. Brasília: Editora da Universidade de Brasília, 1963.

BAUMAN, Z. Globalização: as conseqüências humanas. Rio de Janeiro: Jorge Zahar, 1999.

BORJA, J. As cidades e o planejamento estratégico: uma reflexão européia e latino-americana. In: FISCHER, T. (Org.). Gestão contemporânea - cidades estratégicas e organizações locais. Rio de Janeiro: Fundação Getúlio Vargas, 1997.

BRASIL, CNE/CEB. Parecer 30/2000. Solicita pronunciamento, tendo em vista o Parecer CEB 04/2000. Brasília, Diário Oficial da União, 20 dez. 2000.

BRASIL, CNE/CEB. Parecer O4/2001. Sistemas de Ensino - Estados/Municípios - Entendimento das expressões órgão responsável pela educação e órgãos responsáveis pelos sistemas de ensino. Brasília, Diário Oficial da Uniāo, 23 fev. 2001.

CANDEIAS, A. Processos de construção da alfabetização e da escolaridade: o caso português. In: Stoer, S.; Cortesão, L.; Correia, J. (Org.). Transnacionalização da educação: da crise da educação à "educação" da crise. Porto: Afrontamento, 2001. p. 24-89.

CASTELLS, M. A sociedade em redes. São Paulo: Paz \& Terra, 1999.

CHESNAI, F. A mundialização do capital. São Paulo: Xamã, 1996.

CUNHA, L.A.; GÓES, M. O golpe na educação. Rio de Janeiro: Zahar, 1985.

FIORI, J.L. O vôo da coruja: para reler o desenvolvimento brasileiro. Rio de Janeiro: Record, 2003.

GIDDENS, A. A terceira via: reflexôes sobre o impasse político atual e o futuro da democracia. Rio de Janeiro: Record, 1999.

GIUBILEI, S. Descentralização, municipalização e políticas educativas. Campinas: Alínea, 2001. 
LABOURIAU, F. Sobre um ministério da Educação Nacional. Educação, São Paulo, v. 2, p. 235-248, 1928.

LESBAUPIN, I. Poder local $x$ exclusão social: a experiência de prefeituras democráticas no Brasil. Petrópolis: Vozes, 2000.

MELLO, G.N. A descentralização que vem do centro. Educação Municipal, São Paulo, ano I, n. 1, p. 46-59, jun. 1988.

MÉSZAROS, I. Para além do capital. Campinas: Editora da UNICAMP/ Boitempo, 2002.

MINAS GERAIS. CEE. Parecer n. 500/98. Parecer orientador sobre a organização dos Sistemas Municipais de Ensino. Belo Horizonte, Diário Oficial, 29 maio 1998.

PETITAT, A. Produção da escola. Produção da sociedade. Porto Alegre: Artes Médicas, 1994.

SARI, M.T.; KIRST, T. O município e a educação. Porto Alegre: fAMURS, 1997.

SAVIANI, D. A nova lei da educação: LDB, trajetória, limites e perspectivas. Campinas: Autores Associados, 1997.

SAVIANI, D. Sistemas de ensino e planos de educação: o âmbito dos Municípios. Educação \& Sociedade, Campinas, ano XX, n. 69, p. 119136, 1999.

SILVA, I.C.F. Municipalização do ensino: o avesso de um direito. In GiUbILEI, S. Descentralização, municipalização e políticas educativas. Campinas: Alínea, 2001.

STOER, S. Desocultando o vôo das andorinhas: educação inter/multicultural crítica como movimento social. In: STOER, S.; CorTeSÃo, L.; CorREIA, J. (Org.). Transnacionalização da educação: da crise da educação à "educação" da crise. Porto: Afrontamento, 2001. p. 245-275.

TEIXEIRA, E. O poder local e o global: limites e desafios da participação cidadã. São Paulo/Recife/Salvador: Cortez/EQuip/ufba, 2001.

TEODORO, A. Organizações internacionais e políticas educativas nacionais: a emergência de novas formas de regulação transnacional, ou 
Criação dos sistemas municipais de ensino

uma globalização de baixa intensidade. In: STOer, S.; Cortesão, L.; CorREIA, J. (Org.). Transnacionalização da educação: da crise da educação à "educação" da crise. Porto: Afrontamento, 2001. p. 125-161. 